\title{
Bacteriological Safety Assessment of Municipal Tap Water and Quality of Bottle Water in Dhaka City: Health Hazard Analysis
}

\author{
Saiful Islam, ${ }^{1}$ Housne Ara Begum, ${ }^{2}$ Nilufar Yeasmin Nili $^{3}$ \\ ${ }^{1}$ Department of Microbiology, Stamford University Bangladesh, Dhaka, Bangladesh; ${ }^{2}$ Institute of Health Economics, University of \\ Dhaka, Bangladesh; ${ }^{3}$ Department of Microbiology, Dhaka Medical College, Bangladesh.
}

\begin{abstract}
Bacteriological quality of treated water of different sources was determined by presumptive coliform count. In source-wise distribution of samples, $50 \%$ of mineral water, $87.5 \%$ of filtered water and $100 \%$ of tap water samples were exceeded the drinking water guideline value of WHO. Microorganisms in tap water comprised Escherichia coli spp. (60\%), Klebsiella spp. (40\%), Enterobacter spp. (20\%), Pseudomonas spp. (70\%), Proteus spp. (10\%), Staphylococcus spp. (40\%) and Salmonella spp. (0\%). Furthermore, there was no correlation between faecal coliform and the presence of Salmonella species. Results obtained from this investigation revealed that municipal tap water of Dhaka city was contaminated with a number of enteric bacteria such as $E$. coli. This organism was considered as a good bioindicator model for surveillance studies of antimicrobial resistance. So, only antibiotic resistance pattern of $E$. coli was determined. A total of $10 \mathrm{E}$. coli isolates were used for the sensitivity test. All the isolates were totally resistant to Rifampin and Bacitracin (100\%). Most of the isolates were found highly resistant to Tetracycline $(\mathbf{9 0 \%})$ and Erythromycin $(\mathbf{9 0 \%})$, moderately resistant to Amoxicillin (70\%), Streptomycin (70\%) and Novobiocin $(60 \%)$. On the other hand, the isolates were totally sensitive to Gentamycin $(\mathbf{1 0 0 \%})$ and Kanamycin $(\mathbf{9 0} \%)$ and highly sensitive to Chloramphenicol $(\mathbf{8 0} \%)$.
\end{abstract}

Key words: Municipal tap water, Bacteriological safety assessment, Quality, Bottle water, Health hazard

\section{Introduction}

The World Health Organization informs that every year more than 3.4 million people die as a result of water related diseases, making it the leading cause of disease and death around the world. ${ }^{1}$ In the disease-prone, humid, tropical region of Bangladesh, outbreaks of diarrhoeal diseases, often on an epidemic scale, are not unusual and the possible role of water-borne pathogens in these outbreaks has been emphasized. ${ }^{2}$ Among waterborne diseases of bacterial origin typhoid fever, bacillary dysentery and diarrhoea are common in Bangladesh. ${ }^{3,4}$ Despite the availability and promotion of the use of safe water sources, water-related diseases remain an important cause of mortality and morbidity in Bangladesh ${ }^{5}$

Correspondence:

Dr. Housne Ara Begum

Associate Professor

Institute of Health Economics

University of Dhaka, Dhaka-1000, Bangladesh

Phone: 088029014925 (Res); $088029661920-50$ Ex-8649 (Off)

Email:drhousne@gmail.com and suggest that ingestion of contaminated water is an important mode of pathogen transmission. Even if disinfection is practiced in water supply systems, failure of the disinfection system could result in serious health hazards if contamination occurs.

From the view of public health, it is highly appreciated that potable water supply system should be safe. Water may be polluted at its sources by excreta or sewage, which is almost certain to have pathogenic microorganisms. Potable water system can become polluted with coliform and pathogenic bacteria from normal diseased or carrier human and animal excrement. ${ }^{6}$ As a result, microbiological examination of water should routinely be carried out to monitor and control the quality and safety of drinking water. Although substantial amount of work has been carried out in Bangladesh, unfortunately a little information is available. For this reason, the study was conducted.

The objective of the study was to estimate the overall quality 
of treated water sources in Dhaka city along with the consideration of prevalence of bacterial pathogens in treated water system and correlation of the enteric pathogen with the presence of faecal coliform in treated water. It was also aimed to evaluate the bacteriological quality of drinking water by isolating Escherichia coli (indicator of fecal contamination) in municipal water of Dhaka City and their possible association with drug-resistance.

\section{Methods}

The study was carried out in the Microbiology Laboratory of Stamford University, Bangladesh during the period of January 2009 to April 2009. A total 26 water samples (3 types) were randomly collected from the entire region of the metropolitan city of Dhaka. Water sources were divided into two basic types: tap water and bottle water. For the purpose of sampling, bottle water was further categorized into mineral water and filtered water. Municipal tap water $(n=10)$, bottle filtered water $(n=8)$, and mineral water $(n=8)$ were analyzed. About five hundred milliliter of municipal tap water and bottle filtered water were aseptically collected by presterilized screw capped bottle and transported to the laboratory as early as possible using ice pack insulated box. Mineral water samples were collected from the retail shops in the city of Dhaka.

In order to determine the bacteriological quality of the three types of water samples, three different techniques have been followed. According to the type and load of microorganisms, Spread Plate, Most Probable Number (MPN), Membrane filtration techniques (MF) were applied.

Nutrient agar (Difco, UK), MacConkeys agar (BBL, USA), Mannitol salt agar (BBL, USA), Eosin methylene blue (EMB) agar (Hi media, India) were routinely used to determine hetrotropic plate count, total coliform count, total Staphylococcal count and isolation of E. coli. Xylose Lysine deoxicolate (Hi media, India) agar medium was also used to isolate selective isolation of Salmonella species. For biochemical identification of isolates, Triple sugar iron (Difco), Motility indole urase (Hi media), Simmons citrate agar (Hi media) were used. Muller-Hilton agar (Hi media) was used for antibiotic sensitivity test.

About $0.2 \mathrm{ml}$ raw tap water sample was spread over the surface of the Mac Conkey agar plate and the plates were incubated at $37^{\circ} \mathrm{C}$ for 24 hours. Pink and pale colonies developed on the agar surface were further analyzed for presumptive identification, which was based on cultural, morphological and biochemical properties of the bacterial isolates. All the water samples were periodically analyzed. In case of diluted and repeated samples, only average counts were recorded.

In order to isolate enteric bacteria, MacConkey agar media was used. Bacteria belongs to enterobacteriaceae family were presumptively identified on the basis of cultural, morphological, and biochemical properties. Yellow colonies developed on Mannitol Salt Agar were considered as pathogenic Staphylococcus aureus.

The disc diffusion method known as "Kirby-Bauser Method"7 was used to determine the bacterial susceptibility as well as resistant pattern to different antibiotics. Drug sensitivity and their disease potential were determined by measuring the zone of inhibition by WHO guideline. ${ }^{8}$

Sensitivity test was carried out by Kirby- Bauer disc diffusion method. Eleven different antibiotic disks were used. Total 10 E. coli isolates was used for the sensitivity test. The isolates were categorized into three groups i.e., resistant, intermediate and susceptible on the basis of measuring zone diameter in $\mathrm{mm}$. The results were recorded carefully. Efficiency of antibiotics were determined by means of counting the number of resistant, intermediate or susceptible isolates. 


\section{Results}

Heterotrophic plate count (geometric mean) of mineral water, filtered water and municipal tap water were $1.0 \times 10^{2}, 2.4 \times 10^{4}$ and $3.8 \times 10^{5} \mathrm{cfu} / 100 \mathrm{ml}$ respectively. Heterotrophic plate count of different water samples was illustrated in table 1.

Table 1: Determination of heterotrophic plate count and Total coliform count

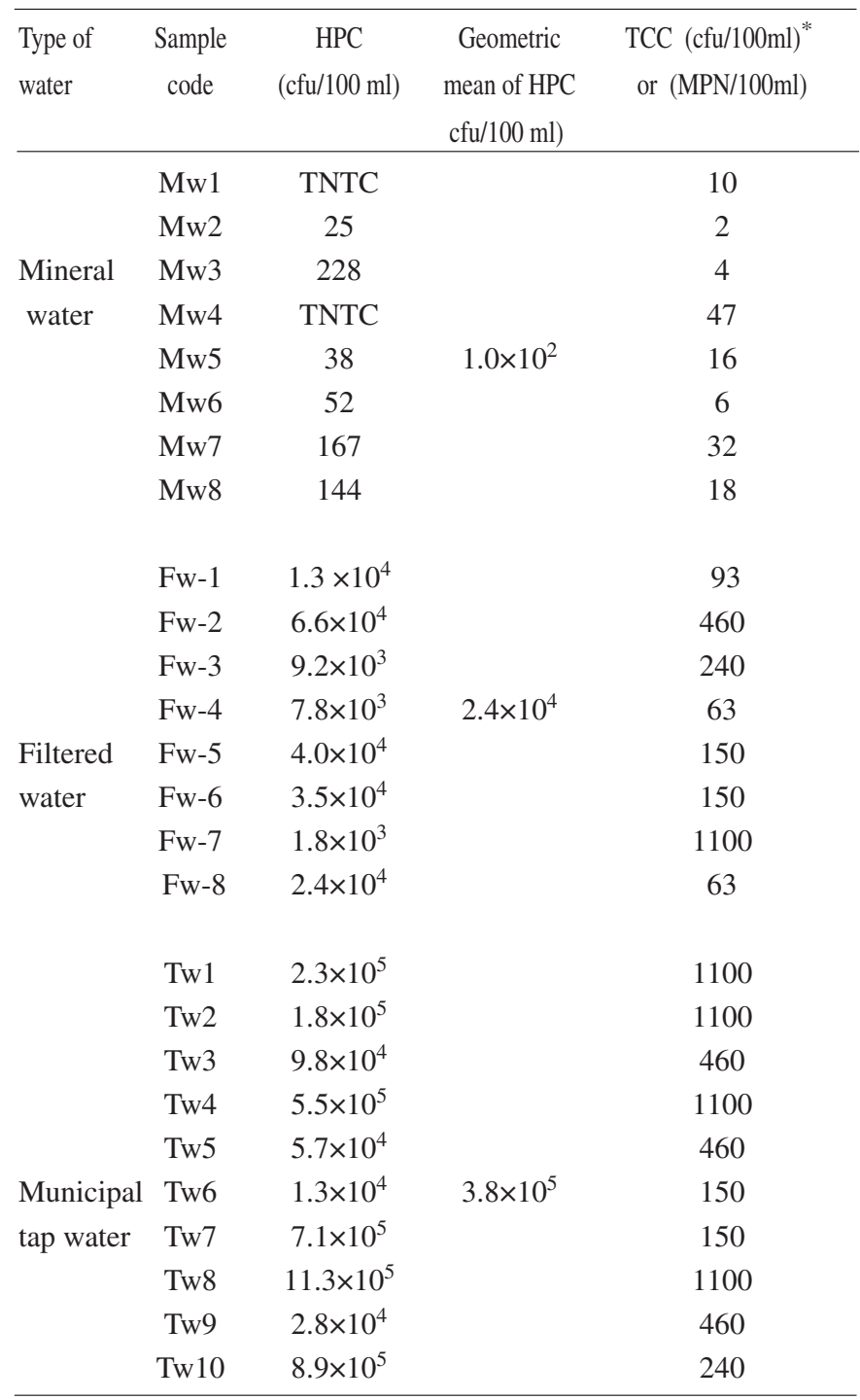

Note: $\mathrm{HPC}=$ Heterotrophic plate count, $\mathrm{TCC}=$ Total coliform count, TNTC $=$ Too numerous to count, ${ }^{*} \mathrm{cfu} / 100 \mathrm{ml}$ was only estimated in case of mineral water.

Bacteriological safety of different sources treated water was determined by comparing presumptive coliform count with the total coliform standard of WHO, 2004. ${ }^{9}$ In source wise distribution of samples, $50 \%$ of mineral water, $87.5 \%$ of filtered water, $100 \%$ of tap water samples were exceeded the
WHO guideline value $(>10 \mathrm{cfu} / 100 \mathrm{ml})$. The results were graphically represented in figure 1 .

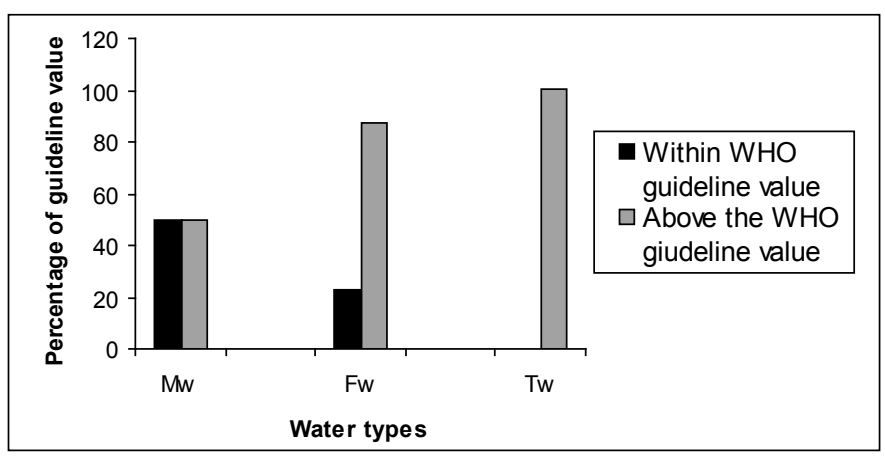

Fig. 1: Percentage $(\%)$ of guideline value of the water sources according to the standard of WHO, 2004 ${ }^{9}$. Key: Mw= mineral water, $\mathrm{Fw}=$ filtered water, Tw=Tap water

Four samples out of ten were contaminated with the organism. About $40 \%$ of the samples were contaminated with pathogenic Staphylococcus spp. Furthermore, Salmonella spp was not found in any tap water sample after the enrichment process. The organisms consistently isolated in this project work as number of positive sample with their percentage frequency of occurrence. On the basis of colonial, microscopic and several biochemical characteristics, microorganisms associated in tap water comprised of Escherichia coli (60\%), Klebsiella (40\%), Enterobacter (20\%), Pseudomonas (70\%), Proteus (10\%), Staphylococcus (40\%) and Salmonella (0\%). Generic percentage of bacterial isolates in tap water was graphically shown in figure 2. From figure 2, it was concluded that there was no correlation between faecal coliform and the presence of enteric pathogen like Salmonella.

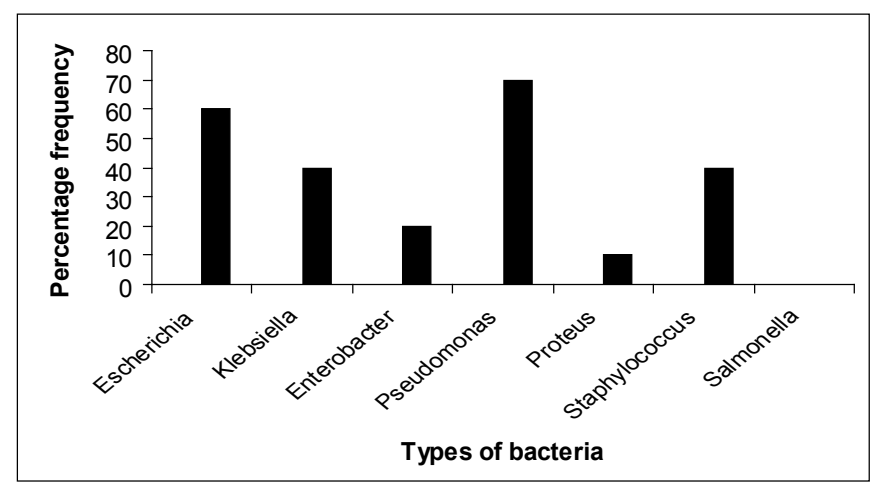

Fig.2: Percentage prevalence of bacterial isolates

Sensitivity test was carried out by Kirby-Bauer disc diffusion method. Eleven different antibiotic discs were used. Total 10 E.coli isolates were used for the sensitivity test. The isolates were categorized into 3 groups i.e resistant, 
intermediate and susceptible on the basis of measuring zone diameter in $\mathrm{mm}$. The results were recorded carefully. efficacy of antibiotics were determined by means of counting the number of resistant, intermediate or susceptible isolates. ${ }^{10}$ All the isolates were totally resistant to Rifampin and Bacitracin (100\%). Most of the isolates were found highly resistant to Tetracycline (90\%), Erythromycin (90\%); moderately resistant to Amoxicillin (70\%) and Streptomycin $(70 \%)$ and Novobiocin (60\%). On the other hand, the isolates were totally sensitive to Gentamycin $(100 \%)$ and Kanamycin (90\%); highly sensitive to Chloramphenicol (80\%) moderately sensitive to Ciprofloxacin $(60 \%)$.

Table 2: Antibiotic sensitivity pattern in percentage

\begin{tabular}{lcccccc}
\hline \multicolumn{2}{c}{ Antibiotic } & \multicolumn{2}{c}{ Resistant } & \multicolumn{2}{c}{ Intermadiate } & \multicolumn{2}{c}{ Susceptible } \\
& No & $\%$ & No & $\%$ & No & $\%$ \\
\hline B & 10 & 100 & 0 & 0 & 0 & 0 \\
AML & 7 & 70 & 3 & 30 & 0 & 0 \\
R & 10 & 100 & 0 & 0 & 0 & 0 \\
E & 9 & 90 & 1 & 10 & 0 & 0 \\
TE & 9 & 90 & 1 & 10 & 0 & 0 \\
NV & 6 & 60 & 2 & 20 & 2 & 20 \\
S & 7 & 70 & 2 & 20 & 1 & 0 \\
CF & 0 & 0 & 4 & 40 & 6 & 60 \\
C & 0 & 0 & 2 & 20 & 8 & 80 \\
CN & 0 & 0 & 0 & 0 & 10 & 100 \\
K & 0 & 0 & 1 & 10 & 9 & 90 \\
\hline
\end{tabular}

Legends: $\mathrm{AML}=$ Amoxicillin; $\mathrm{B}=$ Bacitracin $; \mathrm{C}=$ Chloramphenicol; $\mathrm{CIP}=$ Ciprofloxacin; $\mathrm{CN}=$ Gentamycin ; E= Erythromycin; K= Kanamycin ; NV= Novobiocin; R= Refampin; $\mathrm{S}=$ Streptomycin; $\mathrm{TE}=$ Tetracycline

\section{Discussion}

Heterotrophic plate count bacteria (HPC) are commonly used to assess the general microbiological quality of bottled water. Drinking water quality specifications world-wide recommend HPC limits from 100 to $500 \mathrm{cf} / \mathrm{ml}$ in tap water and $50 \mathrm{cfu} / \mathrm{ml}$ in bottled water. ${ }^{1}$ HPC (geometric mean) of mineral water, filtered water and municipal tap water was $1.0 \times 10^{2}, 2.4 \times 10^{4}$ and $3.8 \times 10^{5} \mathrm{cfu} / 100 \mathrm{ml}$ respectively. HPC was too high in case all types of water. Although high HPC measurements have not been found to correlate with illness incidence and no outbreaks have been directly linked to elevated concentrations of HPC flora in tap water, high HPC measurements do indicate favourable conditions for bacterial regrowth and should be remedied. Bacterial regrowth can promote or cause corrosion of pipes, be responsible for foul-tasting or discoloured water, and promote slime growth. ${ }^{8}$ The worse type of water i.e., tap water was subjected to further analysis. Microorganisms associated in tap water comprised
Escherichia coli (60\%), Klebsiella (40\%), Enterobacter (20\%), Pseudomonas (70\%), Proteus (10\%), Staphylococcus $(40 \%)$ and Salmonella (0\%).

The present study revealed that municipal tap water of Dhaka city was contaminated with a number of bacterial species. A number of factors might be involved for such contamination. Dhaka Water and Sewerage Authority (DWASA) supplies water to user's end through a network of underground pipelines. In Dhaka, the pipe system is very old and most of the pipes are poor in condition. There are leakage and breakage through which contaminants from outside the pipe might enter and get mixed with the supplied water. Due to lack of adequate water these pipes are often out of pressure. There is also an illegal practice of drawing water from pipes by suction. As a result, the pressure in the water main becomes less then the atmospheric pressure. ${ }^{10}$ Both of these phenomena might cause easier entrance of contaminants into pipelines. Moreover, due to improper layout of water supply lines and sewer lines there might be crossing between them. This might cause fecal contamination. Thus, it is very much possible that even if the water, while entering the pipes, satisfy the specification, it might no longer potable and palatable at the user's end.

E. coli is able to acquire resistance easily; therefore it is a good bioindicator model for surveillance studies of antimicrobial resistance. ${ }^{10} \mathrm{~A}$ total of $10 \mathrm{E}$. coli isolates was used for the sensitivity test. The presence of tetracycline, kanamycin and chloramphenicol resistance in $E$. coli from a variety of sources agrees with findings of other studies on the antimicrobial agent resistance of $E$. coli from a variety of different sources throughout the world. Such high incidence of multidrug resistant might be due to indiscriminate use of antibiotics, which may eventually supercede the drug resistant microorganisms from antibiotic saturated environment. In Bangladesh, for many years antibiotic is randomly used for treatment purposes. People are not aware about the schedule use of antibiotics. Thus, resistant strains might be emerged by genetic recombination against one or more antimicrobial agent(s). ${ }^{12}$

The major limitation of the study was time limit; seasonal variation was also not included. Secondly, the study was conducted for only limited number of samples. So, the study should also be performed at different location of Dhaka city along with the consideration of total suspended solid (TSS), turbidity, $\mathrm{p}^{\mathrm{H}}$, seasonal and temperature variation. 


\section{References}

1. The World Health Report 2002. Geneva: World Health Organization, 2001.

2. Khan MR, Saha ML, Kibria AHMG. A bacteriological profile of bottled water sold in Bangladesh. World $\mathrm{J}$ Microbiol and Biotechnol. 1992; 8: 544-5.

3. Parveen, S, Ahmed, M. S.U, Tania, N. Microbial Contamination of Water in Around Dhaka City. Bangladesh J. Sci. industr. Res. 2008; 43(2): 273-6.

4. Begum F, Shahana P, Begum HA, Hoq S. Microbiological quality of different companies mineral and drinking water available in Dhaka city. Bangladesh J Sci and Technol. 1999; 1(2): 209-212.

5. Mitra. The 1991 National Survey on Status of Rural Water Supply and Sanitation for DPHE/UNICEF, Dhaka. Final report, Bangladesh. 1992.

6. Singh A, Mcfeters. Detection method for water borne pathogens. In: Mitchell R (ed.): Environmental Microbiology, John Wiley and sons Inc, New York. 1992.

7. Bauser AW, Kirby WMM, Sherris JC, Truck M. Antibiotic susceptibility testing by a standardized single disc method. Am J Clinic Path. 1966; 145: 225-30.

8. World Health Organization. Guidelines for Drinking Water Quality, 2nd ed. Vol 1: Microbiological Methods. World Health Organization, Geneva 2002.

9. Water, sanitation and hygiene links to health. Geneva. WHO. 2004. Available at: http://www.who.int/water_sanitation_health/publications/ facts2004/en. Accessed 4 April, 2009.

10. Von BM, Marre R. Antimicrobial resistance of Escherichia coli and therapeutic implications. Int J Med. Microbiol. 2005; 295: 503-11.

11. Pipes WO. Microbiological methods and monitoring of drinking water. In: Mcfeters GA (ed.): Drinking water Microbiology: Pringer-Verlag. 1990.

12. Buxton A, Fraser G. Animal Microbiology. Blackwell Scientist Publication. Oxford, London, Edinburg, Melbourne; 1977: pp: 85-6. 